Revista de Ensino em Artes, Moda e Design

Dossiê 6

A modelagem integrada ao projeto de Moda no âmbito do ensio

\title{
MINHA ESCOLHA - SER DOCENTE NO \\ CAMPO DA MODA-DESIGN: MARIA \\ JESUS FARIA MEDEIROS
}

My choice - teaching in the field of fashion design: Maria de Jesus Faria Medeiros

\section{Mon choix - Être professeur dans le Camp de la Mode-Design: Maria de Jesus Faria Medeiros}

\section{Entrevistadora: Mara Rúbia Sant'Anna'}

Entrevista concedida em 26 de abril de 2020, por via eletrônica.

\footnotetext{
${ }^{1}$ Professora efetiva da Universidade do Estado de Santa Catarina. Doutora em História e autora de diversos livros e artigos na área de história da moda, sociedade brasileira e aparência e poder. Atualmente, pesquisa sobre Victor Meirelles e é editora chefe de duas revistas acadêmicas no campo da moda e das artes. UDESC. http://lattes.cnpq.br/8949042412277782. http://orcid.org/0000-0002-9101-5800. E-mail: sant.anna.udesc@gmail.com .
} 


\title{
Resumo
}

O Dossiê n. 6, que engloba discussões sobre modelagem, oportunizou a entrevista com uma professora da área que teve formação bastante diversificada e atua no Bacharelado em Moda da Universidade Federal do Piauí. Sua trajetória de vida começa em Fortaleza, em diversas instituições de ensino como estudante e professora, passa por outras regiões e projetos de nosso país até chegar à Teresina, onde continua lecionando, pesquisando e fazendo a diferença. Por tudo isso ela é inspiradora para os novos profissionais da moda da atualidade.

Palavras-chave: Maria de Jesus Farias Medeiros; UFPI; Ensino Superior em Design de Moda.

\begin{abstract}
Dossier no. 6, which includes discussions about modeling, provided an opportunity for an interview with a teacher in the field who had a very diverse background and works at the Bachelor of Fashion at the Federal University of Piaui. His life trajectory begins in Fortaleza, through several educational institutions as a student and teacher, passes through other regions and projects in our country until he arrives in Teresina, where he continues to teach, research and make a difference. For all these reasons, she is inspiring for today's new fashion professionals.
\end{abstract}

Keywords: Maria de Jesus Farias Medeiros; UFPI;Bachelor of Fashion

\section{Résumé}

Le Dossier no. 6, qu'il s'agit sur le moulage, offre la possibilité d'un entretien avec une enseignante dans le domaine, porteuse d'une formation très diversifiée et qu'est professer à la Faculté de Mode de l'Université Fédérale de Piauí. Sa carrière est débutée en Fortaleza, a continuée em plusieurs endroits jusqu'à Teresina, où ele continue à enseigner est une source d'inspiration pour les nouveaux professionnels de la mode d'aujourd'hui.

Monts-clés: Maria de Jesus Farias Medeiros; UFPI; Enseignement Supérieur en Mode 


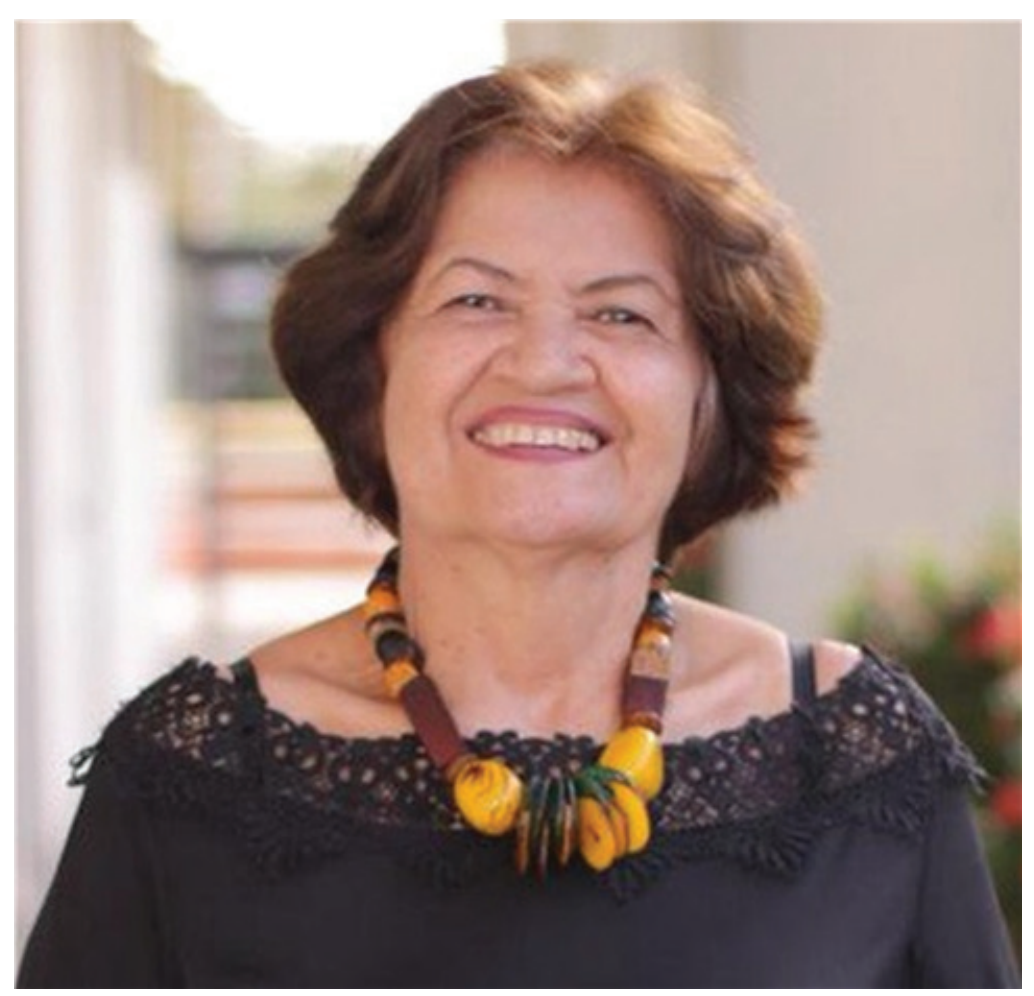

Fotografia de Maria Angélica Chaves - Mageca Alves, setembro, 2019.

\section{Maria de Jesus Farias Medeiros}

Professora concursada da Universidade Federal do Piauí, onde leciona no curso de Bacharelado de Design de Moda, desde 2011. Sua trajetória acadêmica começou em 1977 ao ingressar no curso de Direito da Universidade de Fortaleza, em sua cidade natal. Alguns anos mais tarde, ela realizou a Graduação em Estilismo e Moda pela Universidade Federal do Ceará, concluída em 1998. Como mulher estudiosa, fez vários cursos de pós-graduação lato sensu em Metodologias do Ensino de História, na Universidade Estadual do Ceará, em 2005 e, após, em 2007, em Design Têxtil em Moda, na Universidade Católica do Ceará. No mesmo período, cursou o Mestrado em Administração de Empresas, oferecido pela Faculdade de Economia, Administração, Atuária e Contabilidade da Universidade Federal do Ceará. Em seu mestrado defendeu a dissertação "Construção de marcas de vestuário feminino", em que discutiu sobre as empresas de confecções de vestuário feminino em Fortaleza, a partir da realização de pesquisa de campo com entrevistas de atores sociais do setor estudado, com o objetivo de investigar a utilização de estratégias mercadológicas eficientes. Dentre os outros trabalhos de conclusão de curso que desenvolveu encontram-se os seguintes títulos: "Design de Superfície: Interferências da Arte versus Moda na Criação do Estilista Lino Villaventura" (2007); "Artesanato de rendas: rendeiras da prainha - guardiãs da cultura e memória da arte de fazer renda" (2006) e "As indústrias têxtil e de confecções como mercado de trabalho para o profissional de moda" (1993).

\section{Entrevistadora: Mara Rúbia}

Conte-nos a sua trajetória pessoal e por que escolheu a moda, após ter realizado um curso de Direito? 


\section{Entrevistada: Maria de Jesus}

Antes de tudo, registro meus agradecimentos pelo convite de relatar esta breve trajetória pessoal nos anais desta conceituada Revista de Ensino em Artes, Moda e Design. Importante expor um pouco sobre a minha formação em Direito. Ela rendeu boas oportunidades e julgo ter sido um elo condutor para a escolha da moda. Confesso que tinha vocação para o campo jurídico e até consegui exercer a profissão. Durante o período do curso, eu confeccionava roupas e vendia para umas colegas. Eu tinha habilidades criativas e até artísticas, herdadas do ofício de minha mãe, "modista". Assim, a vocação se desenhava para o campo da moda, mesmo. Então, montei uma loja em sociedade com uma amiga, num espaço legal, mas desisti um ano depois, preferi agarrar a oportunidade de estudar moda, na Universidade Federal do Ceará1 - UFC (1989-1992), Curso Estilismo em Moda, formação equivalente ao nível de tecnólogo (1500h.). Aqui, verdadeiramente, foi o início da minha formação em moda. Foram duas turmas: 33 estilistas formados no programa, para atender as demandas do polo de confecção de Fortaleza. Nossa! Quantas portas foram abertas, pois a qualificação com a determinação faz a diferença. A UFC preconizou o futuro de muitos profissionais com a formação em moda. Em 1994, iniciou a primeira turma do bacharelado de moda. Lembra daqueles 33 profissionais capacitados? Eu fui a única que aproveitou e realizou a graduação em moda, iniciado em 1995 (segunda turma), concluído em 1998. Atuei no mercado prestando consultorias em empresas de confecção, participei de edições de FENIT-SP, SPFW entre outras, até fui contemplada pelo SEBRAE-CE, para fazer um breve curso no FIT- Nova York (1997), 23 anos atrás. E fui me ajustando noutros programas de capacitação, aqueles focados em projetos sociais, comunitários, formato da economia solidaria. Tudo foi importante, agarrei todas as oportunidades, mas destaco aqui um grande desafio. Junto com duas amigas, elaboramos um projeto de capacitação para cooperativas do setor de confecção de roupas no Agreste de Pernambuco, onde ficamos três meses trabaIhando com atividades sustentáveis para a melhoria do trabalho criativo e produtivo naquela região. Nem dá para descrever esta saga. Então, com o diploma de Estilista em Moda, eu consegui mais espaço profissional, mas continuei estudando. Portanto, posso afirmar que minha trajetória conta, aproximadamente, com o mesmo tempo da institucionalização da formação de moda no Brasil.

\section{Entrevistadora: Mara Rúbia}

Logo após a sua formação na graduação em Moda na UFC, você se dedicou à docência, lecionando no SENAI, Faculdade Marista de Fortaleza, Faculdade Integrada do Ceará, Universidade Federal do Ceará, Faculdade Católica do Ceará diferentes disciplinas. Como essa experiência de ensino constitui seu perfil profissional atual?

\section{Entrevistada: Maria de Jesus}

Considero que minhas práticas docentes já tinham iniciado antes, por força do

${ }^{1}$ http://www.ufc.br/. Acesso em 27/04/2020 
meu trânsito profissional. Destemida, com mais autonomia (sou taurina), fiz estreia na docência do ensino superior, no próprio curso de graduação de moda, onde eu era estudante do referido curso. Durante um semestre de 1997, atuei como docente, substituindo a professora Suzana Girard, que morava na França, e fui lecionar a disciplina História da Indumentária e da Moda, da qual poucos conteúdos estavam disponíveis em português. A partir de 1999 até agora, continuo na missão, honrando meu propósito de ser professora. Através do conhecimento constante, sempre me permiti enfrentar desafios. Exemplo: ter passado no concurso para professor efetivo na Universidade Federal do Ceará (2004), instituição que me chancelou o título de Estilista de Moda. Logo, eu seria a primeira docente com a formação específica, lotada no curso. Desisti de assumir por vontade própria e segui determinada na busca de outras possibilidades, mas também sofri duras críticas por esta decisão. Contudo, vejo que tive foco para direcionar meu perfil profissional. Minha contribuição com as referidas instituições de ensino à época tornou possível adquirir ricas experiências. Saiba que consegui trabalhar em três delas ao mesmo tempo. Esse processo de aprendizagem foi fundamental na participação das políticas de educação desses cursos. Internalizar conhecimentos específicos nos permite compreender as práticas pedagógicas, experimentar lideranças. A Faculdade Católica do Ceará - Marista² - foi um marco na minha história. Participei da organização do projeto pedagógico em 2003. Lá permaneci de 2004 a 2011, como docente, coordenadora da graduação tecnológica e também de pós-graduação (lato sensu). Certamente, essas experiências e contribuições, no campo da educação em moda, me levaram a outros destinos.

\section{Entrevistadora: Mara Rúbia}

Desde 2011, você atua na Universidade Federal do Piauí (UFPI), no Curso de Design de Moda, quais foram as motivações para a criação do Curso de Moda em Teresina e como o bacharelado tem contribuído para a região no setor têxtil? Qual a sua participação no crescimento deste curso na região?

\section{Entrevistada: Maria de Jesus}

O Curso de Moda na UFPI ${ }^{3}$, iniciou em 2009 com o nome de Bacharelado em Moda, Design e Estilismo, através do processo de expansão e interiorização da educação superior, com a adesão ao Programa de Reestruturação e Expansão das Universidades Federais (REUNI) ${ }^{4}$. Em 2011, atendendo a política institucional no âmbito do curso, foi criado o segundo curso, com a mesma modalidade do primeiro, ou seja, são dois cursos em turnos diferentes - tarde e noite, com entrada anual de 80 alunos, distribuídos em 40 vagas cada, entre o primeiro e o segundo semestres. Os motivos foram: o crescimento da metrópole, a abertura do mercado de consumo de moda, a expansão do setor de confecção de vestuário-moda na cidade de Teresina e a in-

\footnotetext{
${ }^{2}$ https://www.catolicadefortaleza.edu.br/. Acesso em 27/04/2020.

3 https://sigaa.ufpi.br/sigaa/public/curso/portal.jsf?id=74141\&lc=pt_BR. Acesso em 27/04/2020.

${ }_{4}$ Para saber mais a respeito do programa mencionado, criado no $2^{\circ}$ mandato do Presidente Luiz Inácio Lula da Silva e tendo como Ministro da Educação Fernando Haddad acesse http://portal.mec. gov.br/sesu/arquivos/pdf/diretrizesreuni.pdf. Acesso em 27/04/2020.
} 
teriorização de polos produtivos em algumas cidades do estado. Com a carência de mão de obra especializada, ocorria a importação de profissionais estilistas, designers para suprir alguns segmentos. Tornava-se importante qualificar o setor da indústria. Quanto ao setor têxtil, o estado não dispõe de indústria de tecelagem, malharia entre outros. Decerto, seu desenvolvimento fabril, atende ao elo final da cadeia - produtos confeccionados de moda-vestuário. Sobre o crescimento do curso, a minha participação iniciou em 2011 e começou logo com o desafio para ocupar o cargo de coordenadora, durante dois anos, por votação entre os pares do colegiado. De pronto, contribuí com a organização do Núcleo Docente Estruturante -NDE -, atendendo a Resolução № 01, de 17 de junho de $2010^{5}$, além de dar início à revisão do Projeto Pedagógico de Curso. Procurei realizar uma gestão participativa, compartilhada, colaborativa. Realizamos parcerias com empresas, envolvemos os alunos em eventos local e nacional. Realizamos práticas de publicação de produção escrita, elaboramos projetos, participação em congressos e outros eventos. Assim, continuo na missão sempre aberta para enfrentar novos desafios.

\section{Entrevistadora: Mara Rúbia}

Dentre as disciplinas que você já lecionou, quais as maiores facilidades e dificuldades encontradas no exercício da docência universitária para a formação de profissionais de moda? Há alguma reforma curricular planejada? Haveria necessidade de realizar algo assim, ou o curso atual alcança plenamente seus objetivos?

\section{Entrevistada: Maria de Jesus}

Então! Lecionar é um ato contínuo carregado de desafios, de reinvenção... Disciplinas teóricas apontam facilidades na condução de metodologias. Já, as disciplinas de ordem prática exigem maior rigor na orientação de métodos dos processos criativo/produtivo e, desta forma, podemos dimensionar habilidades e competências individual e coletiva. Nesse sentido, adotamos metodologias ativas ${ }^{6}$, projetuais, além de compartilhar continuamente o desempenho de avaliações sobre o desempenho da aprendizagem. Sabemos que cada disciplina é também avaliada pelo aluno que corrobora no processo de avaliação de resultados ou rendimento. Sobre a reforma curricular, desde 2012, colocamos em pauta a necessidade de revisão do Projeto Pedagógico Curricular, a começar pelo título de Moda, Design e Estilismo. Não é tão fácil atender ao planejamento traçado para a uma conclusão e ainda estar em curso. Realizar ajustes, equivalências de disciplinas, atualizar novas demandas considerar os cenários emergentes e nortear a educação para o futuro, são muitas tarefas a concluir. Sem falar em incluir a revolução digital, midiática, enfim... Dito isso, estamos diante de múltiplos desafios. De verdade, temos urgência nessa revisão.

\footnotetext{
5 http://www.ceuma.br/cpa/downloads/Resolucao_1_2010.pdf.

${ }^{6}$ Para ler mais veja artigo crítico sobre a questão de Valéria Vernaschi Lima em https://www.scielosp. org/article/icse/2017.v21n61/421-434/. E também a dissertação em Educação de Renata dos Anjos Melo defendida em 2017. Disponivel em: https://unisal.br/wp-content/uploads/2018/03/ Disserta\%C3\%A7\%C3\%A30_Renata-dos-Anjos-Melo.pdf
} 


\section{Entrevistadora: Mara Rúbia}

Há programas de formação continuada na UFPI que auxiliam no aperfeiçoamento do exercício da docência?

\section{Entrevistada: Maria de Jesus}

Vamos à questão. Veja, nosso curso pertence ao Centro de Ciências da Educação - CCE. O corpo docente da moda vem se qualificando com resultados satisfatórios, e parte busca programas de formação fora da UFPI, outros na própria IES. Falo da qualificação no nível - mestre e doutor - e, considero algum déficit de ofertas que favoreçam a formação continuada para as diversas áreas, a exemplo de especializações (lato sensu). No caso da moda, já elaboramos programa nesse sentido, mas não houve avanço da proposta. Desse modo, temos a Pró-reitora de Extensão que promove alguns cursos em prol do aperfeiçoamento: formato de seminários, colóquios, palestras. Haveremos de reivindicar e nos organizar sobre o tema. Quanto a mim, busco aperfeiçoamento participando de congressos, seminários, colóquios, conferências, palestras, a maioria em outros estados. Como exemplo, estou participando em Fortaleza, junto a UFC, do projeto de extensão sobre o Movimento da Moda Inclusiva.

\section{Entrevistadora: Mara Rúbia}

No campo da modelagem, tema desse dossiê, quais são, em sua opinião, as maiores facilidades e dificuldades para o estudante de moda dominar esse campo de conhecimento?

\section{Entrevistada: Maria de Jesus}

Tenho muito zelo por este eixo de Tecnologias do Vestuário e considero importante o estudante se envolver na prática do "saber fazer". A atividade se mostra complexa, mas fácil de operacionalizar o rito geométrico dos traçados, com apoio de dados antropométricos, ergonômico, estético, criativo e produtivo na elaboração de gabaritos, o mesmo que desenhos, moldes. Os tipos de modelagem plana, tridimensional e gráfica, bem administrados, asseveram o domínio da aprendizagem com recurso de métodos e processos de criação e interpretação de formas. Vale destacar que o estudo da modelagem, atualmente, conta com uma vasta bibliografia de estudiosos, pesquisadores de excelência no âmbito internacional e em particular aplausos para nossa produção nacional. Vou omitir citá-los, a lista é grande. Dito isto, tem-se como facilidades envolver o aluno em práticas individual e coletiva. Um dado facilitador é que dispomos de laboratórios equipados. Quanto às dificuldades, a mais recorrente é a pouca afinidade com a disciplina prática e até questões de ordem cognitivas que afetam a compreensão de alguns. Por vezes, a dificuldade do aluno ocorre em razão de práticas anteriores malsucedidas. São dados que reverberam no processo ensino e aprendizagem. Nossa função é viabilizar a compreensão do aluno, 
adotando metodologias ativas e envolver todos no processo.

\section{Entrevistadora: Mara Rúbia}

Quais são seus projetos de pesquisa e extensão atuais? Como esses projetos dialogam com o ensino de Design de Moda da UFPI?

\section{Entrevistada: Maria de Jesus}

Na extensão, coordeno um projeto no Núcleo Têxtil de Moda, com mais dois professores e seis alunos bolsistas/voluntários. A parceria é com a comunidade de nome Grota, distante 60 km de Teresina. Trata-se de um grupo de 20 mulheres bordadeiras. A associação vive uma integração colaborativa, comunitária e possui uma escola de moda bem equipada. Nossa gestão com o grupo aplica-se ao conhecimento de conteúdo na tecnologia têxtil, na orientação de métodos de criação de moda, confecção, tecelagem, estamparia planejada em módulos com as diretrizes do design de moda, abarcando as questões ecológicas e sustentáveis no âmbito dos valores das pessoas do lugar. Como resultado de algumas práticas, estamos finalizando um calendário bordado, juntamente com a identidade visual de tag, etiqueta, embalagem e tem lançamento previsto para o próximo salão do livro - SALIPI, em junho de 2020. Pela importância da parceria, o projeto foi renovado. Participo também de um projeto de pesquisa onde avaliamos os nossos alunos egressos, com objetivos de identificar a atuação profissional no mundo do trabalho. Por último, integro um projeto interinstitucional com a UFC sobre o Movimento de Moda Inclusiva, coordenado pela Dra. Araguacy Paixão do curso de Design-Moda-ICA.

\section{Entrevistadora: Mara Rúbia}

Para os atuais estudantes e futuros profissionais de moda que desejam ingressar na docência, qual o recado que você deixa?

\section{Entrevistada: Maria de Jesus}

Serei breve. No atual cenário competitivo, mutante, vislumbramos algumas orientações. A clientela de estudantes de moda, com a formação humana, profissional, estará pronta para o enfrentamento das mudanças da inovação tecnológica, revolução digital, midiática e outros múltiplos desafios. São muitas fronteiras abertas para alcançar o mundo contemporâneo. Ao aluno que deseja ingressar na docência, também encontrará o seu destino. Meu conselho: abrace o ofício com entusiasmo, regado com a relação humana saudável, ilimitada. Abasteça o intelecto de conhecimento, compartilhe saberes, projete expectativas e estude continuamente. A qualificação faz sim a diferença, isto alimenta as habilidades e as competências. Simples assim, não existe receita pronta. Obrigada. 


\section{Entrevistadora: Mara Rúbia}

Agradecendo imensamente a disponibilidade de Jesus, como todos a chamam, chegamos ao final deste bate-papo o qual, antes de tudo, nos demonstra que com determinação e motivação permanente para conquistar mais conhecimento, superar desafios e vencer barreiras, os verdadeiros profissionais alcançam resultados surpreendentes. Filha de uma modista, a cearense foi do Direito ao empreendedorismo, das aulas de história, substituindo a professora francesa, ao ensino de Tecnologia do Vestuário em seu posto atual de docente envolvida, comprometida e acima de tudo inspiradora.

Não é por acaso que o Brasil se destaca no universo acadêmico mundial como o mais denso, multifacetado e amplo espaço de formação de profissionais de moda com qualificação universitária. O sucesso desta posição deve-se ao empenho de inúmeros profissionais e professores como Maria de Jesus Medeiros que nunca se conformou com um "não dá" e, como todos que pensam no coletivo, avançam com determinação e sucesso. ${ }^{7}$

Recebido em: 02/05/2020

Aceito em: 02/05/2020

7 Texto revisado gramaticalmente por Albertina Felisbino, doutora em Letras pela Universidade Federal de Santa Catarina, 1996. lunnaf@uol.com.br 